\title{
Chained behavior as a function of prior exposure to presence and absence of a reinforcing event ${ }^{1}$
}

\author{
STANLEY R. SCOBIE, ${ }^{2}$ ARNOLD KAUFMAN, AND ALAN BARON
} UNIVERSITY OF WISCONSIN-MILWAUKEE

Rats were trained on a two-component chained schedule in which responding to $S_{1}$ produced $S_{2}$ in whose presence a dipper delivered milk. Prior to such training, Ss were preexposed to periods of dipper operation and non-operation either correlated or uncorrelated with $S_{2}$ and $S_{1}$. Acquisition of the chained response was fastest following preexposure to the stimuli paired with dipper operation and non-operation. This result was attributed to mediation by classically conditioned responses since operant behavior observed during preexposure was not a factor.

When rats are preexposed to two stimuli in differential association with the presence or absence of a reinforcing event, subsequent acquisition of an operant discrimination involving these stimuli is facilitated (Bower \& Grusec, 1964; Trapold \& Winokur, 1967). Because the preexposure procedures bear certain similarities to those of classical conditioning, facilitation of subsequent operant behavior has been attributed to mediation by classically conditioned responses.

However, it is also possible that operant behaviors, such as approaching the foodcup, may be acquired during preexposure. In the present experiment, the operant behavior of approaching the foodcup was measured while two stimuli were differentially associated with the presence or absence of a reinforcing event. Subsequently the same stimuli were used to define the two components of a chained schedule in which responding to the first component stimulus produced the second component stimulus associated with reinforcement.

Method

Twenty-four female Holtzman rats, 90 days old, were maintained at $80 \%$ of the free feeding weights of a same-aged control group. The apparatus consisted of four operant chambers (Lehigh Valley) equipped with retractable response levers, and $.01 \mathrm{cc}$ liquid dippers which delivered a solution of $50 \%$ evaporated milk and $50 \%$ water.

There were 34 consecutive daily sessions of 45 min duration. Sessions $1-3$ adapted $S s$ to the stimuli and permitted assessment of lever pressing behavior on the chained schedule in the absence of primary reinforcement. Eight times during each adaptation session the chamber was darkened (S1) and the lever inserted. After three lever presses or $180 \mathrm{sec}$, the chamber was reilluminated $\left(S_{2}\right)$ and the lever retracted. During Sessions 4 and 5 , with $S_{2}$ present and the lever re- tracted, Ss were exposed to response independent operation of the milk filled dipper every $15 \mathrm{sec}$.

In Sessions 6-25 groups of eight Ss were exposed to one of three conditions with the lever always retracted: Stimulus group-the dipper delivered milk every $15 \mathrm{sec}$ in the presence of $\mathrm{S}_{2}$ but not during four $6 \mathrm{~min}$ periods of $\mathrm{s}_{1}$; No Stimulus group-conditions were the same as the Stimulus group except that $S_{2}$ was present throughout; Control group-conditions were the same as those of the Stimulus group except that the dipper operated in both $S_{1}$ and $S_{2}$. For four members of each group, recordings were made of contacts with the wall of the chamber which housed the dipper.

During Sessions 26-34 all Ss were trained on the two component chain. This training was the same as the adaptation training of Sessions 1-3, except that the dipper delivered milk every $15 \mathrm{sec}$ during S2 but not during $S_{1}$.

Results and Discussion

Figure 1 shows contacts with the front wall of the chamber expressed as the ratio of $S_{1}$ rates to $S_{2}$ rates (or, in the No Stimulus group, rates when the dipper was operative and inoperative). The contact behavior of the three groups was similar during the adaptation sessions, when all Ss were treated alike. Figure 1 shows that somewhat more contacts were made during the $S_{1}$ periods than during the $S_{2}$ periods (presumably because of the presence of the lever during the $S_{1}$ periods).

During the preexposure sessions, members of the Control group, for whom the dipper operated without interruption, showed equal rates of contact during

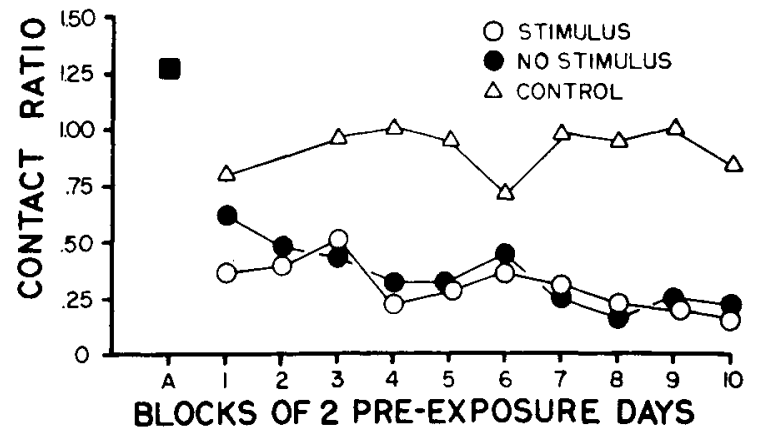

Fig. 1. Contact ratios during adaptation (A) and preexposure (1-10). The first point (square) represents the median contact ratio for all 12 Ss during the three adaptation sessions. 
Table 1. Median response times and interquartile ranges (in sec) during adaptation and acquisition of lever pressing.

\begin{tabular}{|c|c|c|c|c|c|c|}
\hline \multicolumn{2}{|c|}{ Condition } & $\begin{array}{c}\text { Stimulus } \\
\text { Group }\end{array}$ & \multicolumn{2}{|c|}{$\begin{array}{c}\text { No Stimulus } \\
\text { Group }\end{array}$} & \multicolumn{2}{|c|}{$\begin{array}{l}\text { Control } \\
\text { Group }\end{array}$} \\
\hline & Days & $\mathrm{Mdn} \quad \mathrm{Q}$ & Mdn & Q & Mdn & $\mathrm{Q}$ \\
\hline Adapt. & $1-3$ & $6931-86$ & 73 & $34-84$ & 73 & $41-84$ \\
\hline Acq. & $1-3$ & $1914-23$ & 35 & $25-89$ & 40 & $33-49$ \\
\hline Acq. & 46 & $18 \quad 17-21$ & 34 & $19-56$ & 33 & $13-39$ \\
\hline Acq. & $7-9$ & $1711-26$ & 45 & $19-51$ & 36 & $17-42$ \\
\hline
\end{tabular}

the $S_{1}$ and $S_{2}$ periods. By comparison, rates of contact by Stimulus and No Stimulus Ss rapidly declined when the dipper was inoperative. Comparisons based upon each S's median score during the preexposure phase confirmed the reliability of differences in contact ratios between the Stimulus and Control groups $(\mathrm{U}=0, \mathrm{n}=4 / 4, \mathrm{p}<.05$ ) and between the No Stimulus and Control groups $(U=0, n=4 / 4, p<.05)$.

Each S's lever press response time was determined for each block of three days, i.e., during the three adaptation days, and during Days 1-3, 4-6, and 7-9 of training on the chained schedule. Table 1 shows that during the adaptation session response times of the three groups were quite similar. After preexposure, however, there were reliable differences among the groups during Days $1-3$ of training $(\mathrm{H}=7.4, \mathrm{df}=2$, $p<.05)$. Subsequent differences among the groups during Days 4-6 and 7-9 were not reliable. Statistical comparisons substantiated that during the first three training days Stimulus $S$ s responded more rapidly than either No Stimulus Ss $(U=8.5, n=8 / 8, p<.05)$ or Control Ss $(U=11 . n=8 / 8, p<.05)$. Comparisons of adaptation performances to training performances indicated that the Stimulus group showed a reliable decrease in times during Days 1-3 and that all groups showed reliable decreases during Days 4-6 $(p<.05)$.

When performances during acquisition are viewed in relation to performances during preexposure, the conclusion is apparent that discrimination of the periods of dipper operation and nonoperation during preexposure was not sufficient to facilitate acquisition of the lever press response. Facilitation of lever pressing behavior required, in addition, a history of differential association of the two stimuli with operation and nonoperation of the dipper.

The results do not indicate that any operant behaviors related to dipper approaches mediated the faster acquisition of the lever press response to $S_{1}$ by Stimulus Ss. In keeping with the present results, it may be argued that a history of differential association of $S_{1}$ and $S_{2}$ with dipper operation and non- operation resulted in the elicitation of classically conditioned responses to these stimuli, and that it was these responses which mediated the preexposure and training phases.

From the standpoint of a classical conditioning interpretation, the results do not indicate whether faster acquisition of the chained response should be attributed more to responses elicited by $S_{1}$ than to responses elicited by $S_{2}$. The contingencies of the chained schedule were such that the operant lever press had the dual consequence of terminating $S_{1}$ and producing $S_{2}$. On the one hand, the conditioned reinforcement and chaining literature stresses the conditioned reinforcing properties of stimuli associated with unconditioned positive reinforcers (Kelleher, 1966). Alternatively, Leitenberg (1965) and others have pointed to the possibility that stimuli associated with periods of nonreinforcement may acquire conditioned aversive properties, thus making their termination reinforcing.

On the chained schedule, therefore, eventual acquisition of lever pressing in the presence of $S_{1}$ may have been a function of either the development of conditioned aversive properties by $S_{1}$ or conditioned reinforcing properties of $\mathrm{S}_{2}$, or both. The relative superiority of the Stimulus $S s$ in acquiring the lever press response may be attributed to the enhancement of either or both of these properties as a consequence of the preexposure procedures. Worth emphasizing in this connection is that during preexposure $\mathrm{S}_{2}$ was associated with the reinforcing event for all Ss, while $\mathrm{S}_{1}$ was associated with nonoccurrence of the reinforcing event only for the Stimulus Ss.

\section{References}

BOWER, G., \& GRUSEC, T. Effect of prior Pavlovian discrimination training upon learning an operant discrimination. J. exp. A nal. Behav. $1964,7,401-404$.

KELLEHER, R. T. Chaining and Conditioned reinforcement. In W. K. Honig (Ed.), Operant behavior. New York: Appleton-Century-Crofts, 1966. Pp 160-212.

LEITENBERG, $H$. Is time-out from positive reinforcement an aversive event? Psychol, Bull., 1965, 64, 428-441.

TRAPOLD, M. A., \& WINOKUR, S. Transfer from classical conditioning and extinction to acquisition, extinction, and stimulus generalization of a positively reinforced instrumental response. J. exp. Psychol, $1967,73,517-525$.

Notes

1. Based on a master's thesis submitted to the University of WisconsinMilwaukee by the first author and supported by Grant MH 8430 from the National Institute of Mental Health. These data were presented, in part, at the May, 1967 meetings of the Midwestern Psychological Association.

2. Now at McMaster University, Hamilton, Ontario, Canada. 